\title{
USO DE SUBSTRATO ORGÂNICO A BASE DE HÚMUS DE MINHOCA PARA PRODUÇÃO DE MUDAS DE MARACUJÁ E MAMÃO.
}

\author{
Islandia Jesus dos Santos ${ }^{1}$; Felipe Oliveira Nunes ${ }^{2}$; Marina Siqueira de Castro ${ }^{3}$ \\ 1. Bolsista PIBIC/CNPq, Graduando em Agronomia, Universidade Estadual de Feira de Santana, Membro do NEA- \\ Trilhas - Núcleo de Estudos em Agroecologia e Produção e-mail: islandiacfr@ mail.com \\ 2. Pesquisador/Colaborador do NEA- Trilhas, Biólogo, Mestre em Ciências Ambientais pela Universidade Estadual \\ de Feira de Santana, e-mail: nunesfo@mail.com \\ 3. Orientadora/Coordenadora do CEARIS - Centro de Agroecologia Rio Seco e do NEA-Trilhas, Departamento de \\ Ciências Biológicas, Universidade Estadual de Feira de Santana, e-mail: marinacastro@uefs.br
}

PALAVRAS-CHAVE: Agroecologia; Nutrição Orgânica; Mudas.

\section{INTRODUÇÃO}

A Agroecologia é entendida como um enfoque científico destinado a apoiar a transição dos atuais modelos de desenvolvimento rural e de agricultura convencionais para estilos de desenvolvimento rural e de agriculturas sustentáveis (CAPORAL e COSTABEBER, 2002). Para a fertilização do solo, é recomendável a busca por alternativas aos fertilizantes minerais convencionais, de alto custo, de fontes escassas e alto impacto ambiental (LIMA et al., 2001).

O substrato é todo e qualquer material que é usado com o objetivo de servir de suporte para o desenvolvimento de uma planta ou muda até a sua transferência para o viveiro ou para a área de produção (PASQUAL et al., 2001). Os materiais mais utilizados para a produção de substratos orgânicos são os estercos, os compostos orgânicos e os vermicompostos (FINATTO et al., 2014). Para a obtenção de mudas de qualidade, faz se necessária a utilização de substratos com propriedades físicas, químicas e biológicas que favoreçam o crescimento e nutrição mineral da muda. Além disso, a qualidade do substrato depende dos materiais e de suas proporções na composição da mistura (SILVA et al., 2001; NOGUEIRA et al., 2003). A vermicompostagem é a transformação da matéria orgânica recente, em matéria orgânica estabilizada pela ação das minhocas e a microbiota existente no seu trato digestivo (SILVA et al, 2010).

O uso de substratos, especialmente alternativos, de baixo custo e com disponibilidade no local de produção, tem proporcionado qualidade superior às plantas e propiciado incremento a produção. Avaliar o efeito de diferentes formulações de substrato contendo húmus de minhoca para produção orgânica de mudas de maracujá (Passiflora edulis) e mamão (Carica papaya), visando encontrar uma formulação de substrato orgânico que seja adequado para produzir mudas de boa qualidade nas condições locais dos agricultores e que tenha baixo custo. 


\section{MATERIAL E MÉTODOS}

O experimento foi realizado no Centro de Agroecologia Rio Seco (Cearis), unidade da UEFS, situada no município de Amélia Rodrigues- BA.

A produção de húmus foi feita utilizando esterco bovino e palha de capim Brachiária (Brachiaria decumbens) pré-decomposto, em sistema de minhobox. Após digestão do alimento pelas minhocas, restará um material escuro, e úmido chamado "Húmus de minhoca" (EMBRAPA 2006). Foram montados 02 experimentos, cada experimento foi composto de 03 tratamentos, dispostos em blocos casualizados, com 05 repetições em cada tratamento. As proporções do substrato foram: T01 - 10\% Capim triturado; $60 \%$ de Argila; 30\% Húmus; T02 - 10\% Capim triturado; 30\% de Argila; 60\% Húmus; T03 10\% Capim triturado; $10 \%$ de Argila; $80 \%$ Húmus. As mudas foram feitas através do plantio de sementes, que foram semeadas em sacos de polietileno contendo o substrato homogeneizado, três sementes por saco, em ambas as culturas. A cada quinze (15) dias, começando após a germinação, foram coletados a altura das plantas (AP e diâmetro do caule das plantas (DC). E ao final do experimento, quando as mudas estavam no ponto de transferência para campo (60 dias após semeadura das mudas de mamão, e maracujá). Foram coletados os dados de: Comprimento das raízes (CR); Massa seca das plantas (MSP); Massa seca das raízes (MSR). A coleta de dados de matéria seca, procedeu-se colocando as plantas para secar em estufa a $\left(60^{\circ} \mathrm{C}\right)$ até que seu peso se tornou constante, posteriormente foram pesadas em balança analítica. Os dados foram submetidos a análise de variância entre os tratamentos, para verificar se houve diferença estatística entre os mesmos, comparando-as pelo teste de Scott Knott à 5\% Com programa computacional SISVAR (FERREIRA 2000).

\section{RESULTADOS E/OU DISCUSSÃO}

As plantas cresceram e se desenvolveram bem em todos os tratamentos estando prontas para transplante em condições de campo com 45 dias, porem as análises estatísticas comparando as medias de produção encontradas, puderam inferir que o tratamento número 03 , que continha $80 \%$ de húmus de minhoca na composição, apresentou melhor resultados em comparação com os outros dois tratamentos. Não houve diferenças estatísticas entres os blocos, evidenciando que o experimento foi bem conduzido.

No experimento de maracujá, as medias de altura da planta, diâmetro do caule e massa seca da parte aérea e raiz apresentaram diferenças estatísticas sendo o tratamento 3 superiores, pelo teste de Scott Knott a $5 \%$ de probabilidade. O tratamento 2 com $60 \%$ de 
húmus na composição foi superior ao tratamento 1 com $30 \%$ de húmus em relação à altura da planta, diâmetro do caule e massa seca da parte aérea.

Tabela 01: Resumo da análise de variância das mudas de Maracujá submetidas aos tratamentos.

\begin{tabular}{l|lllllll}
\hline TRATAMENTOS & AP $(\mathbf{c m})$ & DC $(\mathbf{c m})$ & MSPA $(\mathbf{g})$ & MSR $(\mathbf{g})$ & CR $(\mathbf{c m})$ \\
\hline T01 & $25.423 \mathrm{c}^{*}$ & $0.250 \mathrm{c}$ & $0.678 \mathrm{c}$ & $0.562 \mathrm{~b}$ & $10.334 \mathrm{a}$ \\
$\mathrm{T} 02$ & & & & & \\
& $26.975 \mathrm{~b}$ & $0.269 \mathrm{~b}$ & $0.938 \mathrm{~b}$ & $0.738 \mathrm{~b}$ & $11.074 \mathrm{a}$ \\
$\mathrm{T} 03$ & $30.325 \mathrm{a}$ & $0.309 \mathrm{a}$ & $1.605 \mathrm{a}$ & $2.238 \mathrm{a}$ & $19.091 \mathrm{a}$
\end{tabular}

*Médias seguidas das mesmas letras, nas colunas, não diferem estatisticamente entre si pelo teste de Scott Knott, a $5 \%$ de probabilidade

Legenda:1 altura da planta (AP), diâmetro do caule (DC), matéria seca da parte aérea (MSPA), da raiz (MSR) e comprimento da raiz (CR).

No Mamoeiro, os resultados foram parecidos as variáveis altura, diâmetro massa seca de parte aérea apresentaram maiores medias para o tratamento 03. O húmus de minhoca foi feito utilizando esterco bovino e material vegetal pré decomposto e estabilizado pela atividade das minhocas, resultando num composto que segundo Carneiro, (1995) melhora as condições físicas do substrato, acelera o processo microbiológico e apresenta uma alta capacidade de troca catiônica, sendo, portanto, rico em nutrientes que são mais rapidamente liberados para as plantas.

Tabela 02: Resumo da análise de variância das mudas de Mamão submetidas aos tratamentos.

\begin{tabular}{l|l|l|l|l|l}
\hline TRATAMENTOS & AP $(\mathbf{c m})$ & DC $(\mathbf{c m})$ & MSPA $(\mathbf{g})$ & MSR $(\mathbf{g})$ & CR $(\mathbf{c m})$ \\
\hline T01 & $27.990 \mathrm{c}^{*}$ & $0.345 \mathrm{~b}$ & $2.367 \mathrm{~b}$ & $0.529 \mathrm{a}$ & $5.597 \mathrm{a}$ \\
T02 & $31.710 \mathrm{~b}$ & $0.349 \mathrm{~b}$ & $3.214 \mathrm{a}$ & $0.6415 \mathrm{a}$ & $6.280 \mathrm{a}$ \\
T03 & $36.783 \mathrm{a}$ & $0.427 \mathrm{a}$ & $3.403 \mathrm{a}$ & $0.714 \mathrm{a}$ & $6.505 \mathrm{a}$ \\
\hline
\end{tabular}

. *Médias seguidas das mesmas letras, nas colunas, não diferem estatisticamente entre si pelo teste de Scott Knott, a $5 \%$ de probabilidade

Legenda:2 alturas da planta (AP), diâmetro do caule (DC), matéria seca da parte aérea (MSPA), da raiz (MSR) e comprimento da raiz (CR).

Aquino e Loureiro (2004) salientam que o húmus de minhoca constitui um excelente fertilizante orgânico que integra bem os substratos para a produção de mudas. Araújo Neto et al. (2009) também cita que o mesmo, por ser rico em fósforo, cálcio e potássio, pode fazer parte da composição de substratos para produção de mudas orgânicas. Cabendo mais adiante novos estudos que avaliem a capacidade de absorção de nutrientes pelas plantas dos compostos orgânicos como o húmus de minhoca. 


\section{CONCLUSÃO}

O húmus de minhoca pode ser utilizado como componente do substrato para produção de mudas de maracujá e mamão, por ser um eficiente fertilizante orgânico e ainda possuir baixo custo caso o agricultor se interesse em produzi-lo na propriedade. As proporções de $60 \%$ e $80 \%$ obtiveram melhores resultados.

\section{REFERÊNCIAS}

AQUINO, A. M.; LOUREIRO, D. C. Minhocultura. Embrapa Agrobiologia.

Seropédica, RJ, 2004.

ARAÚJO NETO, S. E.; AZEVEDO, J. M. A.; GALVÃO, R. O.; OLIVEIRA, E. B. L.; FERREIRA, R. L. F. Produção de muda orgânica de pimentão com diferentes substratos. Ciência Rural, Santa Maria, v. 39, n. 5, p. 1408-1413, ago. 2009.

CARNEIRO, J. G. A. Produção e controle de qualidade de mudas florestais. Curitiba: UFDR/FUPEF, 1995, 451p.

CAPORAL, F. R; COSTABEBER, J. A; Agroecologia: alguns conceitos e princípios. 24 p. Brasília: MDA/SAF/DATER-IICA, 2004

FERREIRA, D.F. Análise estatística por meio do SISVAR (Sistema para Análise de Variância) para Windows versão 5.6 São Carlos. Anais... São Carlos: UFSCar, 2000. p.255-258.

FINATTO, J. et al. A importância da utilização da adubação orgânica na agricultura. Revista Destaques Acadêmicos, v. 5, n. 4, 2014.

NOGUEIRA, R.J.M.C.; ALBUQUERQUE, M.B. de.; SILVA JUNIOR, J.F. Efeito do substrato na emergência, crescimento e comportamento estomático em plântulas de mangabeira. Revista Brasileira de Fruticultura. v. 25, n.1, p. 15-18, 2003.

LIMA, R. L. S; FERNANDE, V. L. B; OLIVEIRA, V. H; et al. Crescimento de Mudas de Cajueiro-Anão-Precoce 'CCP-76' Submetidas à Adubação Orgânica e Mineral. Rev. Bras. Frutic., Jaboticabal - SP, v. 23, n. 2, p. 391-395, agosto 2001.

PASQUAL, M. et al. Fruticultura comercial: propagação de plantas frutíferas. Lavras: UFLA/Faepe, v. 137, 2001.

SILVA, P. R. D.; LANDGRAF, M. D.; ZOZOLOTTO T. C.; REZENDE, M. O. O; Estudo Preliminar Do Vermicomposto Produzido a partir de Lodo de Esgoto Doméstico e Solo. Ecl. Quím., São Paulo, 35 - 3: 61 - 67, 2010.

SILVA, D.B.; SILVA, J.A.; JUNQUEIRA, N.T.V.; ANDRADE, L.R.M. Frutas do cerrado. Brasília: Embrapa Informação Tecnológica, 2001. 179p. 